\title{
The Effects of More Frequent Transfusions upon Bone Loss in Thalassemia Major
}

\author{
F.E.Johnston ${ }^{[11]}$ and J.M.Roseman \\ Philadelphia Center for Research in Child Growth, Philadelphia, Pennsylvania, USA
}

\begin{abstract}
Extract
The thickness of the cortical layer of bone at the midshaft of the second metacarpal was determined radiogrammetrically in a sample of 46 children with thalassemia major, divided into two groups based on the level of hemoglobin maintained through transfusion frequency. The 'high' hemoglobin group displayed levels of nine grams per 100 milliliters or more and the 'low' hemoglobin groups seven grams or less. A group of 23 normal children furnished additional controls. None of the groups differed in the distributions of age, sex or national origin. Though both of the thalassemia groups showed loss of cortical bone relative to the normal, the high hemoglobin group had significantly greater thicknesses of compact bone than the low group. The difference between the thalassemia samples was due to increased periosteal deposition and decreased endosteal resorption.
\end{abstract}

\section{Speculation}

Though more frequent transfusions in thalassemia major seem to have no effect on most growth measurements, it does result in increased cortical bone breadths. This results from a decrease in the excessive hemopoesis associated with thalassemia as well as from an increase in periosteal deposition.

\section{Introduction}

Of all anemias known to medical science, thalassemia results in probably the most drastic changes in affected individuals. Not only are there alterations in the red cell morphology, there are also changes in the external and radiographic appearance of the individual as well as his pattern of growth and development. The results are both distinctive and severe and represent a clinical and research problem to which increasing attention has been paid in recent years [2].

The basic treatment consists of a series of transfusions which maintain a hemoglobin level permitting survival; even so, the life expectancy is less than 20 years. Recently, certain investigators have argued
$[8,9]$ that a regular and frequent transfusion schedule, designed to maintain a level not too far below the normal, results in an improvement in the secondary changes in various organs and tissues which are usually responsible for death. In particular, WoLman [9] has presented clinical data showing that children with thalassemia major with hemoglobin levels consistently in the 8.0 to $9.9 \mathrm{~g} / 100 \mathrm{ml}$ range showed less hepato-, splenoand cardiomegaly than those transfused on a 'demand' schedule, where the hemoglobins ranged from 4.0 to $7.9 \mathrm{~g}$.

These improvements in the clinical picture have led us to investigate whether there are concomitant changes in the other affected areas and aspects. We have not been able to demonstrate any difference in the pattern 
of growth, as indicated by height, weight and skeletal maturation $[4,5]$ which we could attribute to increased hemoglobin levels. Since perhaps the most striking of the secondary alterations involves the skeleton, in many cases providing the prime diagnostic criteria, we have turned our attention to this system. Theskeletal changes consist of enlarged medullary cavities, the result of increased hemopoetic activity due to the decreased erythrocyte life span and a generalized bone loss throughout much of the skeleton [1]. The loss of bone frequently results in pathologic fractures. Since the data of WoLMAN [9] also suggest that the fracture history of individuals who have higher hemoglobins is more satisfactory than those in lower hemoglobin groups, it seems that the parameters involved are worthy of study.

The data to be presented demonstrate that there is, in fact, a decrease in bone loss associated with more frequent transfusions which seems to be the result of a decrease in the excessive hemopoetic activity characteristic of the disease and an increased amount of bone deposition.

\section{Methods}

The children with thalassemia major were either of Greek or Italian origin and were from the New York and Philadelphia metropolitan areas. They had been treated by a number of different physicians and, as individuals, displayed a variety of mean hemoglobin levels. Children with the highest levels, however, came from the Children's Hospital of Philadelphia, where the treatment regimen is designed to maintain, insofar as possible, a high and constant level of hemoglobin. All of the children are part of a comprehensive study of thalassemia major conducted by the Hematology Department of the Children's Hospital and have been followed there and at the associated Philadelphia Center for Research in Child Growth for periods of from two to seventeen years.

After examining the children's records, we selected two groups, each consisting of 15 males and 8 females: a high hemoglobin group, where the levels had been maintained at nine or more $\mathrm{g} \%$ and a low hemoglobin group, with levels of seven $\mathrm{g} \%$ or less. The two subsamples were equated by matching individuals for sex, national origin and chronological age. The mean, within-matched-pair difference in age was zero. Thus, the major difference between the two groups was in the treatment regimen the members had followed.

As an additional control, we selected a group of normal children from the files of the Philadelphia Center for Research in Child Growth, again individually matched by age and sex. The mean within-pair difference between the normals and either thalassemia group was 0.2 months. We did not consider national origin in selecting our normals (though all were white) since our unpublished data show that, in healthy children, there are no differences in cortical bone breadths between children of southern or central and western European ancestry.

The amount of cortical bone was inferred from the thickness of the cortex at the midshaft of the second metacarpal. We obtained this by measuring the total and medullary cavity breadths of the metacarpal on postero-anterior hand-wrist radiographs taken at anode-film distances of $76.2 \mathrm{~cm}\left(30^{\prime \prime}\right)$. Subtraction of the two dimensions gave the summed lateral and medial cortical thicknesses. All measurements were made by a single trained observer using a needle-point sliding caliper reading to the nearest $0.05 \mathrm{~mm}$. Replicate measurements at the Growth Center have, in the past, yielded correlations in the neighborhood of +0.95 . Although morphological differences between the radiographs of normal children and those with thalassemia were obvious, the films of the thalassemia groups were measured without the observer's knowing to which hemoglobin group they belonged.

The radiogrammetric determination of cortical thickness is a technique which is gaining wide acceptance and which is being applied to a variety of areas, e.g., geriatrics [6], nutrition [3] and surgery [7]. Where there is generalized bone loss in the skeleton, this measurement serves as a reliable indicator regardless, apparently, of which long bone is measured.

Results

The two thalassemia groups did not differ significantly from each other in height, weight, chronological and skeletal age, as indicated by mean within-pair differences. Since the individuals in the two groups had been matched by sex and national origin, the major difference between them lay in their hemoglobin levels. As previously shown $[4,5]$, the normal children were taller, heavier and had higher skeletal ages.

The individual cortical thicknesses for the thalassemia groups are plotted against chronological age in figure 1. The two groups are clearly separated, with the greater thicknesses found in the high hemoglobin children and with virtually no overlap between them. It is also evident that no relation between age and cortical thickness exists for the low hemoglobin group, but can be seen to a degree for those with higher levels. We verified this by calculating the coefficients of correlation of cortical thickness and age, which were +0.48 , significant at the 0.05 level, for the high hemoglobin group and -0.02 , not significantly different from zero, for the low hemoglobin group. 


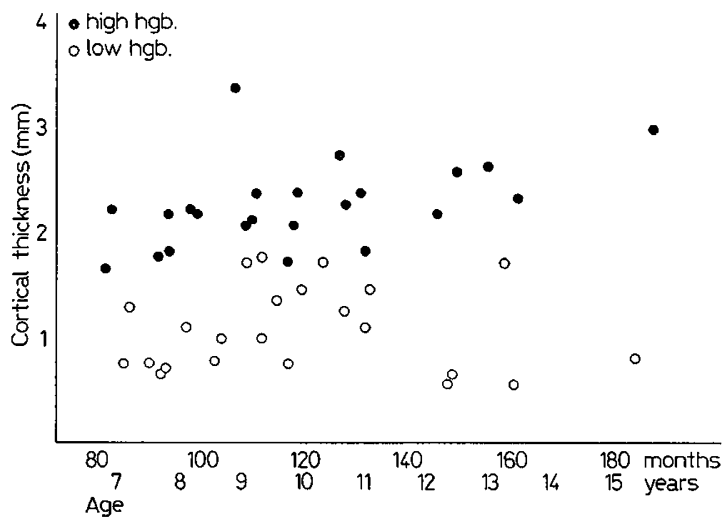

Fig. 1. Cortical bone thickness in thalassemia major. High hemoglobin $=>8 \mathrm{~g} / 100 \mathrm{ml}$; low hemoglobin $=$ $<8 \mathrm{~g} / 100 \mathrm{ml}$.
Table I presents the actual measurements for each of the 69 individuals of the study. In table II we have given the analysis of these data, expressed as mean differences within-pairs of the high hemoglobin thalassemia group compared first to the normals and then to the low hemoglobin group. When they are compared to an equivalent normal sample, children with thalassemia major maintained at higher hemoglobin levels have second metacarpals of the same periosteal breadth but with significantly larger medullary cavity breadths $(p<0.001)$; the thickness of the cortical layer is therefore significantly reduced.

When we compare the two thalassemia groups, we find that all three parameters show significant differences within-pairs. Individuals with the higher hemoglobins have greater periosteal breadths $(\mathrm{p}<0.005)$, reduced medullary cavity breadths $(\mathrm{p}<0.005)$ and,

Table I. Individual measurements of normal and thalassemia samples ${ }^{1}$

\begin{tabular}{|c|c|c|c|c|c|c|c|c|c|c|c|c|}
\hline \multirow{3}{*}{ Sex } & \multicolumn{4}{|c|}{ Normal } & \multicolumn{4}{|c|}{ High- ${ }^{\mathrm{Hgb}}$ thalassemia } & \multicolumn{4}{|c|}{ Low-Hgb thalassemia } \\
\hline & \multirow[t]{2}{*}{$\overline{\text { Age }^{2}}$} & \multirow[t]{2}{*}{$\mathrm{T}$} & $\mathrm{MC}$ & C & \multirow[t]{2}{*}{ Age } & \multirow[t]{2}{*}{$T$} & \multirow{2}{*}{\multicolumn{2}{|c|}{$\frac{\mathrm{MG}}{\mathrm{mm}}$}} & \multirow[t]{2}{*}{ Age } & $\mathrm{T}$ & $\mathrm{MG}$ & G \\
\hline & & & \multicolumn{2}{|l|}{$\mathrm{mm}$} & & & & & & \multicolumn{3}{|c|}{$\mathrm{mm}$} \\
\hline f & 83 & 6.00 & 3.25 & 2.75 & 82 & 6.50 & 4.85 & 1.65 & 86 & 5.50 & 4.20 & 1.30 \\
\hline $\mathrm{m}$ & 84 & 6.50 & 4.20 & 2.30 & 83 & 8.80 & 6.60 & 2.20 & 85 & 6.25 & 5.50 & 0.75 \\
\hline $\mathrm{m}$ & 89 & 6.40 & 4.50 & 1.90 & 92 & 7.40 & 5.65 & 1.75 & 92 & 6.95 & 6.30 & 0.65 \\
\hline$f$ & 94 & 6.40 & 3.65 & 2.75 & 94 & 6.55 & 4.40 & 2.15 & 90 & 6.05 & 5.30 & 0.75 \\
\hline $\mathrm{m}$ & 95 & 7.05 & 4.55 & 2.50 & 94 & 7.75 & 5.95 & 1.80 & 93 & 5.90 & 5.20 & 0.70 \\
\hline $\mathrm{m}$ & 97 & 6.25 & 3.05 & 3.20 & 98 & 8.40 & 6.20 & 2.20 & 97 & 6.65 & 5.55 & 1.10 \\
\hline f & 101 & 6.15 & 3.95 & 2.20 & 99 & 7.00 & 4.85 & 2.15 & 103 & 5.65 & 4.85 & 0.80 \\
\hline $\mathrm{f}$ & 104 & 6.45 & 3.35 & 3.10 & 107 & 6.75 & 3.40 & 3.35 & 104 & 6.80 & 5.80 & 1.00 \\
\hline $\mathrm{m}$ & 109 & 6.95 & 4.70 & 2.25 & 109 & 8.40 & 6.35 & 2.05 & 109 & 7.35 & 5.65 & 1.70 \\
\hline$f$ & 112 & 6.55 & 4.05 & 2.50 & 111 & 6.95 & 4.60 & 2.35 & 112 & 6.30 & 5.30 & 1.00 \\
\hline $\mathrm{m}$ & 112 & 7.20 & 4.50 & 2.70 & 110 & 7.40 & 5.30 & 2.10 & 112 & 7.05 & 5.30 & 1.75 \\
\hline $\mathrm{f}$ & 115 & 6.65 & 3.05 & 3.60 & 119 & 6.00 & 3.65 & 2.35 & 115 & 6.75 & 5.40 & 1.35 \\
\hline $\mathrm{m}$ & 117 & 7.65 & 4.90 & 2.75 & 117 & 6.80 & 5.10 & 1.70 & 117 & 5.95 & 5.20 & 0.75 \\
\hline $\mathrm{m}$ & 120 & 7.00 & 4.55 & 2.45 & 118 & 8.60 & 6.50 & 2.10 & 120 & 7.70 & 6.25 & 1.45 \\
\hline $\mathrm{m}$ & 124 & 8.00 & 4.45 & 3.55 & 127 & 7.90 & 5.20 & 2.70 & 124 & 8.75 & 7.05 & 1.70 \\
\hline$f$ & 129 & 7.65 & 4.85 & 2.80 & 128 & 7.35 & 5.10 & 2.25 & 128 & 6.95 & 5.70 & 1.25 \\
\hline$f$ & 130 & 6.90 & 3.60 & 3.30 & 131 & 6.20 & 3.85 & 2.35 & 132 & 6.75 & 5.65 & 1.10 \\
\hline $\mathrm{m}$ & 133 & 7.65 & 4.40 & 3.25 & 132 & 8.15 & 6.35 & 1.80 & 133 & 7.75 & 6.30 & 1.45 \\
\hline $\mathrm{m}$ & 146 & 8.70 & 5.50 & 3.20 & 146 & 7.15 & 5.00 & 2.15 & 148 & 9.55 & 9.00 & 0.55 \\
\hline $\mathrm{m}$ & 151 & 8.75 & 5.70 & 3.05 & 150 & 8.10 & 5.55 & 2.55 & 149 & 7.75 & 7.10 & 0.65 \\
\hline $\mathrm{m}$ & 158 & 9.55 & 5.05 & 4.50 & 156 & 8.80 & 6.20 & 2.60 & 159 & 7.80 & 6.10 & 1.70 \\
\hline $\mathrm{m}$ & 162 & 9.15 & 6.20 & 2.95 & 162 & 7.85 & 5.55 & 2.30 & 161 & 8.30 & 7.75 & 0.55 \\
\hline $\mathrm{m}$ & 182 & 7.80 & 3.70 & 4.10 & 188 & 8.20 & 5.25 & 2.95 & 184 & 8.45 & 7.65 & 0.80 \\
\hline
\end{tabular}

1 Abbreviations: $\mathrm{T}=$ total metacarpal breadth; $\mathrm{MC}=$ medullary cavity breadth; $\mathrm{G}=$ cortical breadth

${ }^{2}$ Months 
Table II. Comparisons of second metacarpal measurements in normal and thalassemia samples

\begin{tabular}{clccc}
\hline & & \multicolumn{3}{c}{ All measurements in mm } \\
\cline { 3 - 5 } & & $\begin{array}{l}\text { Total } \\
\text { breadth }\end{array}$ & $\begin{array}{l}\text { Medullary } \\
\text { cavity breadth }\end{array}$ & $\begin{array}{c}\text { Cortical } \\
\text { breadth }\end{array}$ \\
\hline $\begin{array}{l}\text { Normal-high-Hgb thalassemia } \\
(\mathbf{n}=23 \text { pairs })\end{array}$ & Diff. & -0.19 & -0.99 & +0.70 \\
& S.D. & 0.21 & 0.18 & 0.12 \\
& $\mathrm{t}$ & -0.890 & -5.472 & +5.867 \\
& $\mathrm{p}$ & $\mathrm{ns}$ & $<0.001$ & $<0.001$ \\
\hline High-low-Hgb thalassemia & Diff. & +0.40 & -0.72 & +1.15 \\
$(\mathbf{n}=23$ pairs $)$ & S.D. & 0.12 & 0.20 & 0.09 \\
& $\mathrm{t}$ & +3.262 & -3.657 & +13.114 \\
& $\mathrm{p}$ & $<0.005$ & $<0.005$ & $<0.001$ \\
\hline
\end{tabular}

1 Mean differences within-pairs in millimeters

2 ns: not significant

consequently, much greater cortical thicknesses ( $p$ $<0.001$ ), the value of Student's- $t, 13.114$, for this last comparison, by far the highest obtained.

\section{Discussion}

It is clear that, in the two thalassemia groups, those children in the higher hemoglobin subsample display greater amounts of cortical bone than those of the low subsample. Since the two groups were matched for the most important developmental variables, it seems reasonable to conclude that the more frequent transfusions of the former have acted to reduce the bone loss characteristic of the disease.

By examining table II, we can determine the mechanism by which greater amounts of cortical bone become associated with higher hemoglobin levels. Compact bone increases through periosteal deposition. Except, perhaps, for the adolescent period in females, this is accompanied by resorption from the endosteal surface. Our measurements of total bone breadths reflect the amount of periosteal deposition, while those of the medullary cavity reflect endosteal resorption. The wider medullary cavity of the low hemoglobin group, relative to the high, indicates that the process of endosteal resorption has been greater in the former. Since the enlarged medullary cavities in thalassemia are believed to be caused by increased hemopoesis, it seems that the more frequent transfusions have effected a reduction in hemopoetic activity. However, it is likewise evident that, even with regular and frequent transfusions, there is increased endosteal resorption in thalassemia; the high hemoglobin group still show significantly wider medullary cavities and reduced cortical thicknesses. Though there is an improvement associated with the more frequent transfusions, the normal condition is still not attained.

Not only is it evident that, with higher hemoglobins, there is a significant reduction in the excessive endosteal resorption, it is likewise clear that the high hemoglobin group displays significantly wider second metacarpals. Since these two groups did not differ in height, weight, chronological or skeletal age, we cannot attribute this to any general growth factor. Rather, it is more logical, at this stage, to conclude that the higher hemoglobins have 'stimulated' greater periosteal deposition of compact bone.

Thus, we may conclude that the maintenance of a higher hemoglobin level through more frequent transfusions in our sample of children with thalassemia major has brought about a normal pattern of periosteal deposition. On the other hand, endosteal resorption, relative to the normal, is still excessive and, consequently, the amount of cortical bone is reduced. However, when compared to children with thalassemia maintained at a lower hemoglobin level, the high hemoglobin group displays increased periosteal deposition, reduced endosteal resorption and greater thickness of cortical bone.

\section{References and Notes}

1. Caffey, J.: Pediatric x-ray diagnosis, 4th ed. (Chicago, Year Book Medical Publishers, Chicago 1961).

2. Fink, H.E. (ed.): Problems of Cooley's anemia. Ann. N.Y.Acad. Sci. 119: 680-685 (1964).

3. Garn, S. M.; Rohmann, G. G. and Nolan, P., Jr.: 
Studies on the development of compact bone in normal individuals and in endocrine and nutritional abnormalities. Prog. Rpt.I, Grant AM03816 (Yellow Springs, Ohio, Fels Research Institute, 1963).

4. Johnston, F.E. and Krogman, W. M.: Patterns of growth in children with thalassemia major. Ann. N.Y.Acad. Sci. 119: 667-679 (1964).

5. Johnston, F.E.; Hertzog, K.P. and Malina, R. M.: Longitudinal growth of children with thalassemia and its relationship to hemoglobin level. Amer. J. Dis. Child. 112: 396-401 (1966).

6. Meema, H. E.: Cortical bone atrophy and osteoporosis as a manifestation of aging. Amer. J. Roentgenol. 89: 1287-1295 (1963).

7. Morgan, D.B.; Pulvertaft, G.N. and Four-
MAN, P.: Effects of age on the loss of bone after gastric surgery. Lancet $i i: 772-773$ (1966).

8. SMrTH, R. S.: The natural history and management of thalassemia major (abstract). Brit. J. Haemat. 12: 659-660 (1966).

9. Wolman, I.J.: Transfusion therapy in Cooley's anemia: growth and health as related to longrange hemoglobin levels. A progress report. Ann. N.Y. Acad. Sci. 119: 736-747 (1964).

10. Supported, in part, by USPHS Grants HD DE 00993, DE 00087 and 1 F3 HD-31, 208-01 and by the Cooley's Anemia Foundation. The cooperation of Dr. I.J.WoLman is gratefully acknowledged.

11. Johnston, F.E., Ph.D., Philadelphia Center for Research in Child Growth, 1701 1/2 Fitzwater St., Philadelphia, Pa. 19146 (USA). 